\title{
Lawrence Livermore National Laboratory Interests and Capabilities for Research on the Ecological Effects of Global Climatic and Atmospheric Change
}

\author{
Jeffrey S. Amthor \\ James L. Houpis \\ James R. Kercher \\ Arno Ledebuhr \\ Norman L. Miller \\ Joyce E. Penner \\ William L. Robison \\ Karl E. Taylor
}

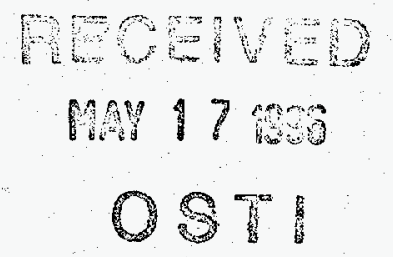

September 1994

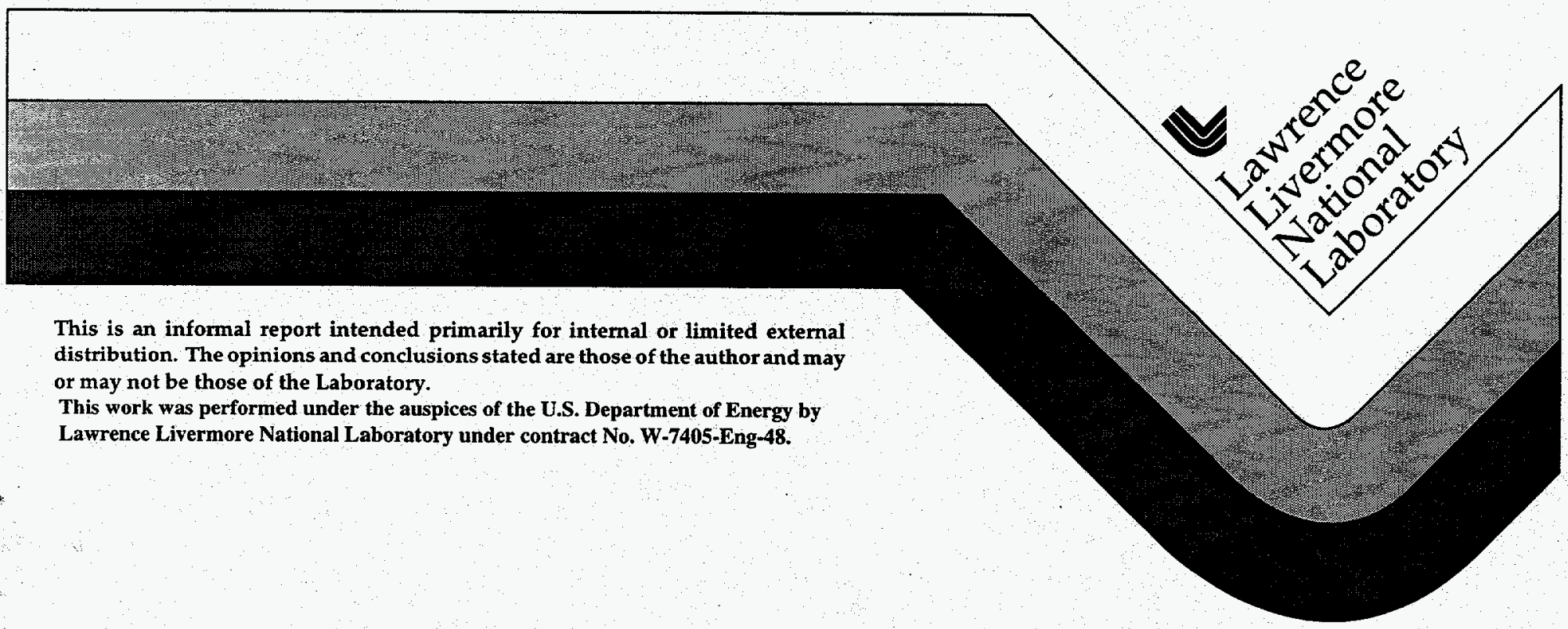




\section{DISCLAIMER}

This document was prepared as an account of work sponsored by an agency of the United States Government. Neither the United States Government nor the University of California nor any of their employees, makes any warranty, express or implied, or assumes any legal liability or responsibility for the accuracy, completeness, or usefulness of any information, apparatus, product, or process disclosed, or represents that its use would not infringe privately owned rights. Reference herein to any specific commercial product, process, or service by trade name, trademark, manufacturer, or otherwise, does not necessarily constitute or imply its endorsement, recommendation, or favoring by the United States Government or the University of California. The views and opinions of authors expressed herein do not necessarily state or reflect those of the United States Government or the University of California, and shall not be used for advertising or product endorsement purposes.

This report has been reproduced

directly from the best available copy.

Available to $\mathrm{DOE}$ and $\mathrm{DOE}$ contractors from the Office of Scientific and Technical Information P.O. Box 62, Oak Ridge, TN 37831

Prices available from (615) 576-8401, FTS 626-8401

Available to the public from the National Technical Information Service

U.S. Department of Commerce

5285 Port Royal Rd.

Springfield, VA 22161 


\section{DLSCLAMMRR}

Portions of this document may be illegible in electronic inage products - Images are produced from the best avallable original document. 


\title{
Lawrence Livermore National Laboratory Interests and Capabilities for Research on the Ecological Effects of Global Climatic and Atmospheric Change
}

\author{
Jeffrey S. Amthor ${ }^{1}$ \\ James L. Houpis ${ }^{1}$ \\ James R. Kercher ${ }^{1}$ \\ Arno Ledebuhr ${ }^{2}$ \\ Norman L. Miller ${ }^{3}$ \\ Joyce E. Penner ${ }^{3}$ \\ William L. Robison ${ }^{1}$ \\ Karl E. Taylor ${ }^{3}$
}

${ }^{1}$ Health and Ecological Assessment Division, L-256

2Advanced Technology Program, L-285

${ }^{3}$ Global Climate Research Division, L-262

Lawrence Livermore National Laboratory

Livermore, California 94550

submitted to

Dr. Jerry W. Elwood

Environmental Sciences Division

Office of Health and Environmental Research

Office of Energy Research

U.S. Department of Energy

Washington, D.C. 20585 


\title{
Lawrence Livermore National Laboratory Interests and Capabilities for Research on the Ecological Effects of Global Climatic and Atmospheric Change
}

\author{
Contributors: Jeffrey S. Amthor, James L. Houpis, James R. Kercher, Arno Ledebuhr, \\ Norman L. Miller, Joyce E. Penner, William L. Robison, and Karl E. \\ Taylor
}

\section{INTRODUCTION}

The Lawrence Livermore National Laboratory (LLNL) has interests and capabilities in all three types of research that must be conducted in order to understand and predict effects of global atmospheric and climatic (i.e., environmental) changes on ecological systems and their functions (ecosystem function is perhaps most conveniently defined as mass and energy exchange and storage). These three types of research are:

(1) Manipulative experiments with plants and ecosystems,

(2) Monitoring of present ecosystem, landscape, and global exchanges and pools of energy, elements, and compounds that play important roles in ecosystem function or the physical climate system, and

(3) Mechanistic (i.e., hierarchic and explanatory) modeling of plant and ecosystem responses to global environmental change.

These three activities-manipulation, monitoring, and modeling-must form the foundation of any large-scale integrated effort to assess overall ecological effects of global environmental change. Manipulative experiments are necessary to determine cause-and-effect relationships between environmental change factors and ecosystems. Monitoring is required to assess present biospheric activity and its links to the global environment. Models are required to integrate knowledge. Models are also needed to make predictions about ecosystem responses to global environmental change that cannot presently be determined by experiment or observation. For example, effects of warming, elevated $\mathrm{CO}_{2}$, and altered precipitation patterns on the whole tropical forest biome cannot be studied by manipulative experiments because the system is too big and complex. Moreover, only parts of that, or any other, biome can be monitored to assess present ecosystem status and function because the spatial scale of biomes is so large. Thus, predictive models remain as the only means of quantifying long-term ecological effects of global environmental change on whole biomes and the biosphere, although models must be mechanistic (i.e., hierarchic, multi-level, or explanatory) and they must be tested (and pass their tests) before they can be used for rational predictions. Models also have the positive attribute of providing a framework around which many studies at a particular site can be coordinated (especially if the research is carried out over many years by different workers). 
Both manipulative experiments and field monitoring (observing) of ecosystem function are needed to parameterize and test models, although model parameterization and testing must be conducted with independent measurements or observations. Model predictions in turn can help guide manipulative experiments and monitoring programs by identifying especially important potential ecological responses, indicatinns, and consequences of environmental change.

From what is already known about plant response to $\mathrm{CO}_{2}$ concentration, temperature, and soil moisture, it is clear that virtually all terrestrial ecosystems will change to some degree in response to global environmental change. For some individuals or populations, the changes may range from loss of productivity to stress-induced morbidity to death. In other systems, the changes to individuals might lead to increased productivity and reduced stress. For ecosystems, these responses range from changes in species composition to overall changes in productivity and nutrient cycling. A reasonable cost/benefit analysis will depend on accurate quantification and prediction of the full range of possible changes. A quantitative predictive capability is required in order to do trade-off calculations to effectively perform assessments and properly analyze the costs associated with reducing greenhouse gas emissions versus amelioration strategies.

Herein, specific experimental programs, monitoring plans, and modeling activities related to evaluation of ecological effects of global environmental change that are of interest to, and that can be carried out by, LLNL scientists are outlined. Several projects have the distinction of integrating modeling with empirical studies resulting in an Integrated Product (a model or set of models) that DOE or any federal policy maker could use to assess ecological effects. We note that any scheme for evaluating ecological effects of atmospheric and climatic change should take into account exceptional or sensitive species, in particular, rare, threatened, or endangered species.

\section{NEW APPROACHES TO IDENTIFY AND QUANTIFY BIOSPHERIC RESPONSE TO GLOBAL ATMOSPHERIC AND CLIMATIC CHANGE}

One incontrovertible facet of global environmental change is that atmospheric $\mathrm{CO}_{2}$ concentration is increasing annually. During the past 200 years, the $\mathrm{CO}_{2}$ concentration of the atmosphere has increased from $c .280 \mathrm{ppmv}$ to $c .360 \mathrm{ppmv}$. All reasonable analyses indicate that the $\mathrm{CO}_{2}$ concentration of the atmosphere will continue to increase for many decades to perhaps a few centuries. The present increase in atmospheric $\mathrm{CO}_{2}$ concentration is largely due to fossil fuel combustion, although human land-use (e.g., deforestation) is also important; present release of $\mathrm{CO}_{2}$ to the atmosphere from the biosphere as a result of land use change is thought to be equivalent to $c .25 \%$ of the carbon released during fossil fuel combustion, but this was a much larger fraction in the past.

Terrestrial ecologists recognize two important outcomes of the continuing global increase in atmospheric $\mathrm{CO}_{2}$ concentration:

(1) Carbon dioxide is the substrate of photosynthesis, it inhibits photorespiration, and it may slow plant (autotrophic) respiration, which taken together mean that plant $\mathrm{CO}_{2}$ assimilation and growth may be greater now than in preindustrial times and 
they may be further enhanced in the future by continued increases in atmospheric $\mathrm{CO}_{2}$ concentration. Whether this $\mathrm{CO}_{2}$ "fertilization effect" carries over to whole ecosystems, thus increasing ecosystem productivity and carbon storage, is an open, and vigorously debated question. Some have proposed that nutrient limitations, e.g., low soil nitrogen or phosphorus, might be limiting plant response to $\mathrm{CO}_{2}$ such that elevated atmospheric $\mathrm{CO}_{2}$ will not significantly increase ecosystem productivity. Others have suggested that the positive response to elevated $\mathrm{CO}_{2}$ is independent of other limitations on growth, or may even be greater for stressed compared to unstressed plants and ecosystems.

Climate models predict that increased atmospheric $\mathrm{CO}_{2}$ concentration will cause (or is causing) global warming and perhaps changes in precipitation amounts and geographic patterns. In general, terrestrial ecologists assume that increasing temperature will stimulate plant and soil respiration processes. Thus, the combination of elevated $\mathrm{CO}_{2}$ (and therefore enhanced photosynthesis) and elevated temperature might result in increased or decreased ecosystem productivity, or perhaps cause no net change. Effects of changes in precipitation are even less certain, in part because predictions of present and future precipitation amount and pattern by climate models are problematic.

These potential effects of elevated $\mathrm{CO}_{2}$ on plants and ecosystems demand further research and clarification. Long-term (1 year or longer) responses to elevated $\mathrm{CO}_{2}$, or to elevated $\mathrm{CO}_{2}$ in combination with elevated temperature and altered precipitation patterns, have been determined for only a few ecosystems. In particular, very little is known about responses by forests and tropical grasslands to elevated $\mathrm{CO}_{2}$, which are responsible for a large majority of global photosynthesis and terrestrial carbon storage.

In the remainder of this section, ideas for research aimed at determining effects of atmospheric and climatic changes on terrestrial ecosystems are put forward.

\section{A. Observations (Measurements) of Biome Boundary Movements}

A change in atmospheric composition or climatic patterns (i.e., warming and altered precipitation amount and timing) may affect the geographic distribution of vegetation and ecosystems. That is to say, biome boundaries may be altered by global environmental change. This potential response to global environmental change is perhaps the most important that has been proposed and could eventually affect all biomes on earth. Ecosystems at the edge of biome boundaries are probably most vulnerable to climatic change because they are presumably approaching, or are at, the "edge" of climatic and other environmental "windows" favorable for such ecosystems. Many ecologists believe that changes in vegetation patterns (biome migration) may result in at least temporary losses of carbon from the biosphere to the atmosphere. This would represent a positive feedback on global warming if warming is caused by elevated $\mathrm{CO}_{2}$ and warming causes biome migration. Biome migration remains a critical unknown with respect to global environmental change impacts and feedbacks on the biosphere.

It has been suggested that warming $\left(c .0 .5^{\circ} \mathrm{C}\right)$ has occurred during the past 100 years. Such a change in temperature might be expected (according to some ecosystem and biome location models) to cause a shift or migration of biome boundaries. Models that predict 
and explain ecosystem and biome boundaries should be exercised at the regional and global scales to predict which biomes are most likely to be migrating significant distances in response to present atmospheric and climatic changes. Corroboration of predictions of biome boundary movement as a result of warming would come from demonstrations of such a phenomenon occurring at present and over the last 100 years.

The large-scale nature of both observations and modeling required to meet this primary need of quantifying biome migrations will necessitate collaborative efforts among many scientific teams. All important biomes and their boundaries must be considered. Several methods of study could be used.

Soil carbon isotopic signatures, specifically $\delta^{13} \mathrm{C}$, can be used to investigate recent shifts (or migrations) from $\mathrm{C}_{3}$-dominated to $\mathrm{C}_{4}$-dominated ecosystems (or vice versa) at specific locations. This can serve as a nearly direct measurement of significant changes in some biome boundaries. Replacement of $\mathrm{C}_{3}$-forests by $\mathrm{C}_{4}$-grasslands (or vice versa) in response to recent environmental changes is one important potential example. This method will presumably not, however, be successful in distinguishing changes from one $\mathrm{C}_{3}$ to another $\mathrm{C}_{3}$ ecosystem or from one $\mathrm{C}_{4}$ to another $\mathrm{C}_{4}$ ecosystem. Thus, some biome migrations will not be detectable with this method.

Although not a new methodology, more comprehensive use could be made of palaeodata to examine previous climate-terrestrial biosphere interactions. Particular topics of interest include (1) glacial/interglacial changes in terrestrial carbon pools, (2) biome boundary responses to past climate and atmospheric $\mathrm{CO}_{2}$ concentration, and (3) changes in ecosystems that are particularly important to non- $\mathrm{CO}_{2}$ greenhouse gas production, such as wetlands.

Large-scale field campaigns, perhaps using satellite imagery, comparing present to past biome boundaries is required. Field studies should focus on biome boundaries identified by available models as being most vulnerable to environmental change in order to search for responses that may be most easily observed. Such activities are not now extensive and new monitoring programs using existing data of past biome boundaries and assessing present and future biome boundaries are therefore needed. Monitoring programs must divorce any observed movement in biome boundaries caused by atmospheric (e.g., $\mathrm{CO}_{2}$ and pollutant concentrations) or climatic (e.g., temperature and precipitation) changes from boundary movement caused more directly by human activities such as urbanization, deforestation, and other land-use changes.

\section{Program to Detect Vegetation Response (Biome Boundaries and State of Vegetation) to Global Change Using Integration of Hyperspectral Remote Sensing and Plant Modeling}

There have been no observations of ecological change that have been reliably and conclusively linked to global environmental change. That is, the biosphere continually responds to weather, so vegetation response to a weather fluctuation is difficult to distinguish from a response to changes in the long-term average, i.e., climate. We suggest the development of a Hyperspectral Remote Sensing System (HRSS) to assess vegetation response to global climatic change. In such a program, advanced remote sensing technology originally developed for Defense Program applications could be used in conjunction with new analytic techniques for interpretation of remotely sensed data. New, high spectral resolution remote sensing techniques show promise of estimating canopy 
chemical composition parameters that can be used to elucidate ecosystem properties. Estimation of plant canopy biochemical concentrations via measurable variables aboveground can be used to infer rates of flux, and controls of fluxes, of carbon, nitrogen, and water by ecosystems and landscapes.

The technical objectives of this program are to (1) develop and apply techniques for detecting biospheric response to global environmental change and (2) detect and quantify large-scale biochemical concentrations. To achieve both of these objectives, we suggest the use of observations from unmanned air vehicles (UAV's) and advanced high performance imaging sensors developed by Defense Programs in conjunction with ecological models and ground studies.

Recent analyses imply that transition zones between vegetation types or biomes may be sensitive to changes in climate. In examining the paleoecological record, the response of transition zones to environmental change can exhibit very complicated (often non-linear) behavior. Transition zones can be distinguished into two types: rapid (or abrupt) and gradual. It has been suggested that the rapid transition zones (ecotones) are actually bi-stable flip-flops that occur because some process such as competition dominates the dynamics rather than responses to weather, whereas gradual transition zones (ecoclines) occur where the environment (weather) dominates the dynamics. Thus, attempts to discover ecological effects of moderate climatic change by detecting changes in ecotones (e.g., tree lines at high altitudes) might fail, while ecoclines may respond more strongly. These considerations suggest the approach of focusing detection on gradual transition zones between vegetation types. A gradient in woodland density along a regeneration gradient has been observed with MSS satellite data, and the detection of such gradients with the HRSS on a UAV platform should prove even easier since the resolution can be arbitrarily set (within limits) to the size of structures that are selected for detection.

One problem in detecting response to climatic change is that of separating those responses from ecological fluctuations that occur due to (1) local or short-term weather changes and (2) natural ecological changes (e.g., succession). The first distinction can be achieved by long-term (many years) observations and by global observations. The case for global observations rests on the idea that climatic change will occur globally (even though there may be latitudinal variation in the change) as indicated by general circulation model (GCM) calculations. The program would have to establish the statistical basis for testing this by sampling many locations around the globe with the same classification of transition zones in several biomes. That is, if the earth's distribution of vegetation changes in response to climate, it should be possible to filter the noise and extract the signal by repeatedly sampling this distribution at many places. To avoid the problem of natural ecological changes, one could examine undisturbed ecosystems and discard observations that follow known successional development or recovery from disturbance. Developing a global approach is practical because the platforms for the project (UAV's) are relatively low cost and guidable.

Another approach to global environmental change effects detection is to monitor physiological changes that occur because of changes in stress due to changes in weather. Physiological response should precede community-level changes so that early detection might be achieved. At high latitudes, greenhouse warming might reduce stress and at middle to low latitudes stress might increase. Lignin levels in foliage have been used as an indicator of stress and can be detected by spectroscopic means with advanced sensor 
technology of an HRSS. Leaf water content has been observed by several researchers using remotely sensed data and this can be used as another indicator of stress. In this approach, measurements of natural seasonal variation in water content are averaged out and the annual changes are the indicators of interest to detect effects of long-term environmental change. Arguments given above for separating large-scale and long-term changes from short-term and local changes also apply to this approach.

Plant leaves have complex spectral characteristics due to a plethora of biochemicals. Instruments needed to observe these features require both high spectral and spatial resolution and high detection sensitivity. Nearly all of the forest work to date has made use of available sensors and instrumentation, such as the Airborne Imaging Spectrometer (AIS), the Airborne Visible/Infrared Imaging Spectrometer (AVIRIS), and other experimental sensors, which were not developed with the explicit measurement of plant biochemical properties in mind. Spectra of lignin, protein, cellulose, and starch all have absorption features in the near-infrared wave band and remote spectral observations can generate quantitative information about the amount of carbon, nitrogen, and water in plant canopies. The design of the imaging spectrometer should be optimized to collect this data.

UAV's in addition to offering low cost remote sensing and data collection platforms also provide flexibility in experimental viewing strategies. The use of multiple look angles and off-nadir viewing, "retrodirection" viewing within the solar plane, and spectraltemporal oversampling for increased signal-to-noise ratio are all possible. By adjusting the altitude of data collection, one can easily vary the spatial resolution of the measurements. Thus, fine and coarse resolution data can be obtained on the same landscape systems with the same sensor. By controlling the collection of data, one can observe similar systems geographically separated or follow gradients. This results in both a flexible and economical approach to global data sampling and can generate calibrated high spectral resolution data for correlation to satellite data sets.

Modeling has been successfully used in conjunction with remote sensing both in data interpretation and model testing. To aid the analysis of data, this program should construct models of plant dynamics incorporating physiology, productivity and element cycling, community-competition and response to environmental variables, and landscape dynamics. Model development could proceed rapidly by using components from the existing stock of ecological and plant models.

The information gathered by this project would contribute to on-going projects to monitor global environmental change. The knowledge of how and where environmental change is affecting the biosphere will have implications for the economy of the US and indeed for all the nations of the earth. If, as some have suggested, there will be regional "winners" and "losers" due to global environmental change, it is in the national interest of the US to know this as soon as possible.

\section{B. Free-air $\mathrm{CO}_{2}$ Enrichment (FACE) Experiments}

Free-air $\mathrm{CO}_{2}$ enrichment (FACE) techniques-which are adaptations of previous successful free-air release systems used for air-pollution-effects research-have been used effectively in several short-statured ecosystems such as crops and pastures. A FACE system is now being tested for use in a forest by DOE. It is important that future FACE experiments address responses to $\mathrm{CO}_{2}$ (and other environmental variables) in ecosystems that are 
quantitatively important to (1) atmospheric $\mathrm{CO}_{2}$ concentration, (2) the global carbon cycle, and (3) goods and services required by humanity.

\section{FACE in Combination with Elevated Temperature}

A new and needed approach to studying ecological effects of elevated $\mathrm{CO}_{2}$ and increased temperature is to combine a FACE facility with elevated temperature in the field. For example, an elevated temperature treatment (also in a free-air, i.e., nonchamber, mode) in a split-plot design, with FACE arrays as plots split with ambient and elevated temperature treatments, could be developed. As with other free-air exposure facilities, a FACE-elevated temperature field experiment would allow the cooperative research of a large team of scientists from several laboratories and universities because of the relatively large treatment areas compared to typical glasshouse and open-top chamber experiments. (The cost of a FACE experiment is much greater than typical chamber experiments, however, and FACE cannot be used to answer all elevated $-\mathrm{CO}_{2}$ effects questions. Various chamber systems are required for studying many cause-and-effect relationships with individual plants and small plant communities.) Several FACE-elevated temperature experiments, using several ecosystem types, should be conducted for a period of ten or more years so that longer-term ecosystem responses can be quantified. The national laboratories offer advantages over universities and research institutions for such large, long-term, and interdisciplinary experiments.

\section{FACE in Combination with Carbon Isotope Manipulations}

The source $\mathrm{CO}_{2}$ for elevated- $\mathrm{CO}_{2}$ treatments typically has a different isotopic signature than the ambient atmosphere, i.e., it is usually depleted in both ${ }^{13} \mathrm{C}$ and ${ }^{14} \mathrm{C}$. Because of this, ecosystems used in FACE experiments will contain a unique isotopic signature that can be followed through time to help quantify carbon pool turnover times. This will be especially important for litter and belowground carbon pools. Control (ambient $\mathrm{CO}_{2}$ ) FACE arrays should also be used to introduce a unique isotopic signature to the control areas so that pool turnover times can be studied there as well. Specifically, $\mathrm{CO}_{2}$ greatly

enriched in ${ }^{13} \mathrm{C}$ can be added continuously to the control areas, but at a concentration so small as to leave the total $\mathrm{CO}_{2}$ concentration relatively unchanged. The present atmospheric $\mathrm{CO}_{2}$ pool contains $c .1 \%{ }^{13} \mathrm{C}$ and that fraction can be tripled in FACE control areas with only a $2 \%$ increase in total $\mathrm{CO}_{2}$ concentration. Without carbon isotope manipulations in both ambient and elevated $\mathrm{CO}_{2}$ treatments, determination of effects of elevated $\mathrm{CO}_{2}$ (compared to present ambient $\mathrm{CO}_{2}$ ) on turnover times will be problematic.

\section{FACE for Ecosystem Model Testing}

While FACE experiments are important to the global change research community, they and all other field experiments are in the end site-, time-, and treatment-specific sets of observations. Only a few environmental variables can be manipulated in experiments at any one time, and only short-term experiments (on ecological scales) can be conducted with available resources. In order to extrapolate to other sites, to other $\mathrm{CO}_{2}$ concentrations, to other climatic regimes, to other ecosystems, and across longer time scales, predictive 
models are needed. For example, a detailed mechanistic (bottom-up, hierarchic, explanatory) model of wheat is being developed (at LLNL) in conjunction with the ongoing USDA/DOE FACE wheat experiments in Arizona. The model is being independently tested with FACE experiment data. If it passes its tests (both with FACE experiment results and with other wheat growth and physiology observations) it will be applied globally to wheat growth and production (wheat is the world's major crop). The wheat model structure may be used as an example for development of a suite of mechanistic crop models that explicitly and intrinsically account for crop (plant, soil, and microclimate) responses to atmospheric $\mathrm{CO}_{2}$ concentration, temperature, precipitation, nitrogen inputs, humidity, wind, air pollution, solar radiation (cloudiness), and other important environmental variables. Existing published crop models are demonstrably inadequate with respect to accuracy and realism in their predictions of crop response to environment, and a new generation of mechanistic crop models is called for by USGCRP initiatives. LLNL has established ties with the USDA/DOE FACE program in the area of crop modeling, and would like to enhance those links to the mutual benefit of USDA and LLNL.

Similarly, FACE experiments with other ecosystems provide excellent tests of plant and ecosystem growth models with respect to effects of elevated $\mathrm{CO}_{2}$. Model testing is, in fact, one of the most important reasons for conducting FACE experiments.

\section{Standardized Plant Physiological Research Methods to take Special Advantage of Multiple Elevated- $\mathrm{CO}_{2}$ Research Sites}

An important method of adding value to existing and planned ecological research sites is to work across multiple sites and experiments with a common set of measurements or models. One example relates to the relatively recently discovered, and not yet understood, inhibitory effects of elevated $\mathrm{CO}_{2}$ on plant respiration. Experiments have shown that $\mathrm{CO}_{2}$ inhibits respiration in leaves, shoots, and roots. This has important implications for the global carbon cycle, and represents a negative feedback on increasing atmospheric $\mathrm{CO}_{2}$ that potentially applies to all terrestrial ecosystems. It may be a fundamental and universal effect of atmospheric change on ecosystem productivity. One mostly unanswered question is whether long-term elevated $\mathrm{CO}_{2}$ treatment results in acclimation of respiration to elevated $\mathrm{CO}_{2}$ and compensates for the inhibition of respiration observed in shorter-term elevated- $\mathrm{CO}_{2}$ experiments. A single, i.e., "standard," method and protocol of measuring plant respiratory response to elevated $\mathrm{CO}_{2}$ could be developed (based on previous research in this area conducted by LLNL and ORNL scientists in collaboration with university scientists), made portable, and then moved from one long-term elevated- $\mathrm{CO}_{2}$ experiment to another. This would standardize an important set of measurements across $\mathrm{CO}_{2}$-enrichment protocols and ecosystems, and would facilitate the development of a coherent theory of respiratory response to elevated $\mathrm{CO}_{2}$ that could then be applied globally in models (at LLNL and ORNL or elsewhere) of the terrestrial biosphere.

Plant respiration is used only as an example, albeit an important one. Standardized and portable methods could be applied to the study of photosynthesis, transpiration, and perhaps plant growth and ecosystem carbon storage. 


\section{Network of Long-term Eddy Correlation Measurement Sites to Quantify Present Ecosystem Function and Test Models of Ecosystem Metabolism}

Eddy correlation is a well developed micrometeorological method of measuring atmospheric exchange of mass, sensible heat, and momentum by ecosystems. (The first published report of comprehensive $\mathrm{CO}_{2}$ flux measurements made by eddy correlation in the field was based on instrumentation developed at LLNL.) Measurement "footprints" are typically hundreds to thousands of square meters in size, depending on measurement and ecosystem heights. Eddy correlation measurements have not typically been conducted at any site for more than one growing season or one year, although Harvard Forest in central Massachusetts is the notable exception. A network of long-term, i.e., continuous and multi-year, eddy correlation measurement sites involving many (ideally all) important ecosystem types (e.g., tropical moist forest, tropical seasonal forest, tropical savanna, temperature deciduous forest, temperate evergreen forest, temperate grassland, boreal forest, arctic tundra, etc.) could be used to assess ecosystem responses to some climatic factors by relating measured fluxes of mass, heat, and momentum to intraseasonal, interseasonal, and interannual cycles of weather and other environmental variables. To reduce the likelihood of unique (i.e., nonrepresentative) observations, several eddy correlation measurement sites should be established in each important biome. The DOE ARM site in Oklahoma should form an important component of such a network. Perhaps portable eddy flux towers could be developed and used to survey multiple sites (or multiple ecosystems and biomes) within relatively small geographic areas in short-term but intensive campaigns.

A network of eddy correlation measurement sites would also contribute to the improvement of land-surface flux parameterizations in climate models. Better parameterizations are needed for a better understanding of effects of the biosphere, and any biospheric responses to environmental change, on atmospheric composition and climate.

Because of the large and dynamic footprint of eddy correlation measurements above ecosystems, eddy correlation cannot be used to assess ecosystem response to elevated $\mathrm{CO}_{2}$ because the delivery of controlled $\mathrm{CO}_{2}$ to large areas of an ecosystem from above the ecosystem-which would be required for use with the eddy correlation method-is too difficult and expensive. Nonetheless, eddy correlation measurements should be used to test ecosystem metabolism models with present environmental conditions. Proper, that is mechanistic and predictive, models (will) include biochemically based models of photosynthesis which can themselves be tested with elevated- $\mathrm{CO}_{2}$ experiments conducted in branch chambers of whole-plant or small-community open-top chambers. Ecosystem metabolism and growth models tested with eddy correlation measurements in present environmental conditions with photosynthesis submodels tested with elevated- $\mathrm{CO}_{2}$ experiments using various chamber techniques, will provide the best available tools for predicting long-term responses of ecosystem functions to elevated atmospheric $\mathrm{CO}_{2}$ concentration and climatic change. The models must of course pass their tests before confidence can be attached to their predictions. 


\section{E. A Biosphere Model Intercomparison Project (BMIP)}

Many models of the terrestrial biosphere and its components are being developed in parallel by different research groups. These models are based on somewhat di sing viewpoints, and can have differing objectives. It is unre? rnnable to assume th a single general model of the biosphere will emerge from these present modeling eff 8 Nonetheless, a systematic means of testing and comparing models of the $t$ biosphere-including models of biosphere components such as general canof: specific ecosystem models, or general primary production models-is needer $t$ systematic comparison of models will help assess strengths and weaknesses of indivic i models, which will contribute to the best possible predictions of ecological responses to global environmental change. We suggest that a Biosphere Model Intercomparison Project (BMIP) be established, and we note that such a program exists now for the testing and comparison of climate models with the aim of providing the best possible predictions of future climate; namely, the LLNL Program for Climate Model Diagnosis and Intercomparison (PCMDI).

Overall goals of a BMIP might be the determination-or development-of models suitably accurate and robust enough to predict

(1) Local, regional, and global ecological effects of environmental change,

(2) The future terrestrial carbon cycle and its role in atmospheric $\mathrm{CO}_{2}$ concentration, and

(3) Terrestrial biosphere-atmosphere interactions that can be included in climate models so that feedbacks between the biosphere and the atmosphere are properly accounted for in predictions of future climate.

In any case, a clear list of project objectives will facilitate the timely production of useful project output that will be of benefit to the entire global environmental change research community. The national laboratories are best suited for the coordination of such a large, and in many respects interdisciplinary, program of model evaluation.

Several hurdles or questions exist with respect to the implementation of a BMIP. These include:

(1) How can models developed with different goals in mind be compared?

(2) Which criteria are most important in model testing with respect to understanding and predicting ecological effects of global environmental change?

(3) What core set of model tests would be most useful?

(4) Which data should be used to test models for accuracy and realism?

Other question also exist. We propose that these difficulties should be addressed during the early stages of a BMIP development, but that organization of a BMIP not be held back because of present difficulties in answering these questions.

One important link between a BMIP and environmenti' ineasurements used to test biospheric models should be made with respect to carbon isotope $\left({ }^{13} \mathrm{C} /{ }^{12} \mathrm{C}\right.$ and $\left.{ }^{14} \mathrm{C} /{ }^{12} \mathrm{C}\right)$ measurements in soil, ocean, and atmosphere. Carbon isotope measurements provide some bounds on the relative importance of ocean and land in the global carbon cycle. Moreover, 
temporal, latitudinal, and longitudinal gradients in atmospheric isotope ratios can be used to indicate locations of carbon sources and sinks on land. Accurate models of the biosphere (coupled with models of atmospheric transport and ocean carbon cycling) will predict these same atmospheric gradients, so isotopic measurements can be used as a powerful test of model performance. [Carbon isotope measurements can be made accurately and quickly by accelerator mass spectrometry (AMS) at the existing LLNL Center for Accelerator Mass Spectrometry (2.A below).]

All the modeling work proposed herein could be tested within a BMIP and all the experimental and observational programs would provide data important to model evaluation and intercomparison.

\section{F. Effect of Climatic Change on a Network of Local Landscape Sites}

This program is for integrated modeling and experimental studies at each appropriate DOE facility (beginning with the NERP facilities) to develop site models coupling community ecology with ecosystem functioning and analysis spanning the spatial scales from the physiological to landscape ecology. The resulting model or models for each site could be used for site management, scientific studies of the scaling problem, detection of landscape or local response to environmental change, mitigation strategies at the local or landscape scale, detailed studies of carbon sequestration in ecosystems, local studies of biodiversity, and the basis for the construction of larger scale models or initiation of larger scale studies. This program would require a substantial experimental and observational program to coincide with and support model development. The experimental programs would be at both the local ecosystem and landscape scales. The experimental program would include site ecosystem and vegetation mapping for landscape studies.

This project would grow out of the existing NERP system but would require a substantial increment of new funding because each site would be a fully integrated multidisciplinary project. There would be two levels of integration for this project: at the site level and the network level. The network level integrating function would be set up in a subproject on inter-site comparison of the functioning of the ecosystem and landscape models. Thus, the site models would be designed for intercomparison of inputs and outputs from the outset of the project. The subproject integrating across the network would emphasize the network aspect of the project. This project would include a good opportunity for coupling models between ecological disciplines and across scales.

The value of the site models to DOE is as a management tool for each site and as an on-the-shelf standing resource at the local- to landscape-level to be instantly available for studying climatic change or any other problem that DOE becomes responsible for such as air pollutant effects. As a resource or management tool, it would be useful to build front-ends or model interfaces so that they could be managed easily and intelligently in a decision-support mode by policy makers who might not be experts in modeling or computer science.

\section{G. Global Inventory, Global Vegetation Response Model, and Global Ecosystem Model}

We recommend that DOE supports development of global models and databases related to 
terrestrial biospheric productivity and element cycling. These models should be tested within the BMIP (1.E above), which would depend in part on suitable global " tabases. An example of one program of modeling and database creation follows.

This initiative would produce three products:

(1) A world map (computer data bases) of an inveritory of the geographis tri on of the dominant plant species, important associated species, and rare endangered species; standing crops of carbon and nitrogen and their ies including net primary production; vegetation respiration; soil respir $\quad 1$; and net ecosystem production,

(2) A fully dynamic model of the spatial dynamics of vegetation at th .obal scale, i.e., response, including spatial movement of vegetation, to climatic and atmospheric $\mathrm{CO}_{2}$ changes, and

(3) A model of the ecological functioning of the biosphere including element cycling and ecosystem productivity.

The vegetation response model and the global biosphere functioning model would be coupled. This is a far reaching program that would have a lifetime of about 15 to 20 years. It would have to be coordinated through international organizations (e.g., UN, SCOPE, and IIASA), and to be fully successful, would require small levels of funding from each nation for sampling and mapping its territory. DOE would obviously have to coordinate this project with other global change projects of other agencies (e.g., EPA, NASA, and Department of Interior's National Biological Survey). The DOE function in this proposal could be model integration and data management. In addition, there is expertise within each of the national laboratories to help in the inevitable swarm of subprojects of sampling and ecosystem analysis.

\section{Global Inventory}

Accurate prediction of global consequences to terrestrial ecosystems of environmental change requires well founded knowledge of the existing standing crops of the various carbon pools and pools of associated elements that are intimately coupled to carbon such as nitrogen. Reliable global databases will also be critical to the BMIP (1.E above).

Many existing databases are in need of significant improvement. For example, aboveground biomass for the Canadian boreal forest was recently estimated by random sampling of this biome. It was found that previous estimates of the Canadian boreal forest biomass overestimated standing crops by a factor of about four. Previous biome estimates had been made by extrapolating from standing crops at a few sites by multiplying by biome area. All other estimates for all other biomes are still based on this extrapolation technique (multiplying land area by biomass measured at a few sites). New and extensive global sampling and mapping programs are needed.

Global Model of Vegetation Response to Climate and $\mathrm{CO}_{2}$ Level

Climate influences the distribution and growth of vegetation on the Earth. Conversely, vegetation is an important component in establishing the lower boundary conditions of the 
atmosphere and the exchange of greenhouse gases between land and atmosphere. Thus, vegetation is important in determining the future course of climatic change. We suggest that DOE sponsor the development of a model of the response of vegetation distribution (see also 1.A above) to changes in climate and atmospheric $\mathrm{CO}_{2}$ concentration. Many authors have suggested a range of climatic factors controlling plant growth, species range, and distribution of morphological types of vegetation. These factors include degree-day temperature "sums," annual precipitation, ratio of actual to potential evapotranspiration, average monthly temperature for months greater than $0^{\circ} \mathrm{C}$ (biotemperature), pre-dawn leaf water potential, mean temperature of the warmest (or coldest) month, annual range of mean monthly temperature, lowest average monthly precipitation, and average precipitation of the warmest month. Increased levels of $\mathrm{CO}_{2}$ are known to substantially increase photosynthesis and growth in $\mathrm{C}_{3}$ plants and to slightly increase photosynthesis and growth in $C_{4}$ plants. As a result of these plant-level changes, canopy shape and density are altered. Moreover, some plants proceed through phenological development at an accelerated rate and show an increase in seed production number and weight, which can lead to increased reproductive potential.

A physiologically based, fully dynamic model of production, succession, dieback, dispersal, and invasion of vegetation for the Earth's land surface is needed. The model should be constructed by dividing the Earth's land surface into grid cells covering the continents. Dispersal distances should be a key consideration in fixing the cell grid size. Dispersal distances should be determined from paleobotanical reconstructions or modern experiments. Within each grid cell, there will be a model of physiological response and growth for each vegetation type or dominant species. This model should calculate the state of the soil and the physiological state of the vegetation including such variables as soil water content, evaporation, transpiration, net photosynthesis, and productivity as functions of temperature, precipitation, atmospheric $\mathrm{CO}_{2}$ concentration, humidity, solar irradiance, and soil properties. Growth, dieback, and mortality should be determined for the vegetation types present in the grid cell. Effects of $\mathrm{CO}_{2}$ on water-use-efficiency should be included in these calculations. Competition should be modeled within each grid cell. The spread or dispersal of propagules between grid cells should be included. Model performance should be tested against the paleobotanical record. Steady state values can be compared against current observations. The model should be used to analyze the dynamics of global vegetation adjustment under climatic change associated with increase greenhouse gas levels. Rates of advance can be monitored in model output and analyzed in order to develop methodologies for detecting actual vegetation adjustments, i.e., strategies for field detection of response or adjustments to climatic change will be developed from model behavior.

Note that the structure and subject of a program of this type lends itself to involvement with many key topics in the ecological subdisciplines. One such topic is scaling from small field study sites to landscape or global scale analyses or assessments. 


\section{Global Biosphere Model of Productivity and Cycling}

We suggest that DOE support the development of one or more models of the terrestrial biosphere that functions with short time steps $(c .1 \mathrm{~h})$ and that predicts net primary productivity, decomposition, and biogeochemical cycling at a spatial scale of resolution fine enough that the model can be tested for local sites. The short time scale of resolution is needed to capture the strong diurnal patterns of ecosystem function (e.g., photosynthesis and transpiration), so that the model can be tested with eddy correlation measurements (30-60 min), and so that the time scale is consistent with models of atmospheric physics and chemistry that the model can provide input to. The model should fully couple water, carbon, and nitrogen dynamics in the atmosphere-plant-soil system. There is sufficient experience in the DOE laboratories upon which to build this model. The goal of this project would be to model the functioning of the biosphere with sufficient accuracy that high levels of confidence can be placed on future extrapolations of atmospheric $\mathrm{CO}_{2}$ content for various scenarios of fossil fuel forcings and land-use changes.

The terrestrial model should include the dynamics of peat formation in boreal and alpine systems and the accumulation of carbon in peat. Effects of irradiance, atmospheric $\mathrm{CO}_{2}$ concentration, soil moisture, and state of the carbon and nitrogen in vegetation and soil pools on peat development and carbon accumulation should be included in the model. The peat formation model is important because so much of the current standing crop, and present accumulation, of carbon in boreal systems is in peat.

\section{H. Effect of Climatic Change on the Ecology of the Regional Basins of the USA}

There would be many uses of a set of regional models that cover all the ecosystems of the US. The models should link vegetation, soils, animal populations, mesoscale weather, atmospheric chemistry, and surface hydrology. The models could be used coordinate the production of new vegetation and animal maps (computer data bases) for the regions of the US. This information would be used to drive the models. The program would produce models that couple the dynamics of plant physiology, nutrient cycling, vegetation community dynamics, and animal invasions and population dynamics. In addition, long term vegetation dynamics in response to climatic change would be addressed. Thus, there would also be a regional paleoecology component of the program. This project would also address the problem of spatial scaling, coupling between disciplinary expertise and coupling disparate models, and introduce the coupling of spatial animal population modeling (spread of pests) to vegetation modeling.

The surface of the US. would be divided up into the major drainage basins and models developed for each one. Basins should be used instead of biomes because basins won't shift with climatic change but biomes might. Basins are hydrologically complete systems; there is hydrologic communication within basins but not between basins. In short-term models, the dynamics of each basin are more or less independent of the others. Some coordination between basin teams would be required, however, for long-term models that simulate long-term dynamics including vegetation movement in response to climatic 
change. From a research management point of view, ESD/DOE has about as many national laboratories as basins. (The Mississippi Valley might best be divided into two or three sub basins. Also, from a research management point of view, ESD would be free to encourage competition among the laboratories or teams of laboratories for basin projects.)

DOE could make use of these models for looking at effects of global climatic change, costs of mitigation strategies for climatic change, effects of drought, desertification, and regional air pollution effects.

The mapping component of this program would have to be coordinated with other Federal agencies and programs such as EPA's EMAP program, USGS, and the National Biological Survey (NBS).

\section{Air Pollution as a Component of Global Environmental Change}

Present and future atmospheric changes include several quantitatively important phytotoxic pollutants such as ozone in the lower troposphere. There are at least three major problems associated with studying air pollution effects on ecosystems such as forests, which are dominated by long-lived plants:

(1) Identifying differences in response to pollution by seedlings (which can be studied easily) and larger or mature plants (which cannot be studied easily),

(2) Conducting experiments for sufficient time to determine long-term effects of pollution, and

(3) Quantifying effects of pollutants on belowground processes such as root growth and death and soil organic matter oxidation.

For convenience, most air-pollution studies use potted seedlings as test material. Seedling responses to pollutants, however, need not reflect responses of larger trees or whole ecosystems. Long-term experiments, though well-known to be required to address important questions concerning overall long-term effects of air pollution on terrestrial ecological systems, are costly and by definition time consuming. These factors have worked against long-term studies in most cases. In spite of the importance of belowground processes to carbon storage and cycling on land, access to belowground processes in intact ecosystems is problematic and has contributed to present ignorance of belowground responses to pollution (and belowground responses to elevated $\mathrm{CO}_{2}$ and warming, for that matter).

Several innovative procedures could be used more extensively to circumvent these difficulties:

(1) Seedling responses to pollution can be compared with mature vegetation that has been grafted to seedling root-stock,

(2) Branch exposure chambers that can accommodate either seedling material or branches from mature trees can be used to compare metabolic activity of both seedlings and older branches exposed to similar treatments, and

(3) Rhizotrons can be used to visually monitor root activity and to allow access to soil and root sampling for trees exposed to various levels of phytotoxic air pollutants. 
Long-term experiments, and therefore long-term research facilities, will be required in many cases.

Importantly, these same techniques can be applied to elevated- $\mathrm{CO}_{2}$ treatments and even to the important combinations of elevated $\mathrm{CO}_{2}$ and elevated phytotoxic pollutants. When individual plants are studied, be it with elevated $\mathrm{CO}_{2}$, elevated temperature, elevated pollutants, or a combination of these factors, multiple species must be studied to determine interspecies differences (or similarities) across ecosystems.

\section{J. Community to Landscape Scale Effects of Climatic Change on Forests}

There have been suggestions in the literature that the rate of forest dispersal on the landscape will be insufficient to keep pace with projected rates of change of climate (see also 1.A above). There have also been suggestions of widespread water stress resulting from projected changes in temperature, even for forest systems enjoying relatively well-watered conditions. These suggestions should be investigated with community-level and landscape-level models. We suggest that DOE sponsors the study of the response of

forest systems to climatic change at the forest stand spatial scale $\left(-400 \mathrm{~m}^{2}\right.$, population and community level) using the individual-based community (gap) models, at the small area scale $\left(-8 \times 10^{4} \mathrm{~m}^{2}\right)$ using the small-area models constructed as groups of gap models, and at the landscape scale $\left(-8 \times 10^{6} \mathrm{~m}^{2}\right)$ using landscape models. In gap models, the establishment, growth, and death of each individual tree of each species is modeled. Gap models are sensitive to climate (growing season temperature, precipitation), contain shading competition, and some contain fire ecology or nutrient cycling. We suggest the strategy of extending the spatial scale of gap models by constructing a small-area model as a grid of gap models. In small-area models, neighboring grid cells interact by the dispersal of seeds, the spread of fire, and possibly inter-cell shading. We suggest that landscape-level models be constructed by aggregating species variables in communitylevel models situated on a grid. All three models should be tested against forest plots (including fire study plots) maintained by the US Forest Service and US Park Service.

The considerable amount of experimental information that has been accumulated on effects of increased $\mathrm{CO}_{2}$ on productivity, growth, and water-use efficiency should be used to develop empirical response functions for individuals to be incorporated into the gap and small-area models. These models will then translate these effects at the organism level to community and small area scale responses. Information derived from the gap model can then be used to develop response functions to increased atmospheric $\mathrm{CO}_{2}$ concentration for the landscape model. Thus, there is a natural progression of integration up the organizational hierarchy. This progression of models can be used to study the effects of changing climate (temperature and precipitation) on the communities and the landscape. One could determine how global climatic change affects (1) rates of species invasions, (2) necessary and sufficient conditions for the establishment of local refugia or relic stands, (3) conditions for the absence or presence of hysteresis in responses, and (4) responses in stand productivity, small area productivity, and landscape productivity. The results of the productivity studies will be important in providing guidance for the development of global-scale carbon cycling models that are an important component of climate system models. In particular, these results will be important when estimating the potential for carbon sequestration in forested systems. 
Another example of scaling from local site experiments to regional response is the problem of peat formation discussed under the Global Biosphere Model of Productivity and Cycling (1.G above). We suggest that the proper modeling analysis of this problem is through the implementation of a forest gap model with detailed moss community dynamics and resulting peat formation as a function of climate, soils, topography, and forest composition. This model should then be extrapolated to the regional scale for use in global models by analysis of successive runs of inputs randomized by Monte Carlo. With this approach, the extrapolation from local to larger scales would follow naturally.

\section{K. Ameliorating Adverse Effects of Global Environmental Change}

There is potential for ameliorating adverse effects of environmental change on both human-managed and unmanaged ecosystems, although prospects for successful activities are probably higher in managed ecosystems.

Crops and managed pastures are the source of most human food, and both increasing atmospheric $\mathrm{CO}_{2}$ concentration and climatic change might impact their productivity and sustainability. Crop breeding has the potential to take advantage of increasing atmospheric $\mathrm{CO}_{2}$ through even greater use of photosynthate for desired end products such as grain, but the more important response to environmental change may be related to high temperature tolerance, particularly of developmental and growth processes during grain filling in grain crops. Much work needs to be conducted in screening and identifying genotypes of major food crops (e.g., wheat, rice, maize, sugar cane, soybean, bean, potato, sorghum, cassava, sweet potato, sugar beet, sunflower, and rye) and fiber crops (e.g., flax and cotton) for susceptibility and tolerance to higher temperature. Genotypes not adversely affected by elevated temperature should be studied as candidates for replacement of existing genotypes. Some of the adverse effects of elevated temperature on crops can be circumvented by changing the time and location of crop growth, but limits to this strategy exist with respect to changing crop locations by availability of appropriate land for crop production. If warming exceeds a few degrees Celsius in some regions, cool-season crops may need to be replaced by warm-season crops.

Some species in forest ecosystems may be adversely affected by climatic change (and some may benefit significantly from elevated $\mathrm{CO}_{2}$ ). In managed forests, e.g., plantations, tree varieties not negatively impacted by environmental change might be identified (through vigorous and large-scale screening programs) and planted to replace varieties susceptible to environmental change. In previously unmanaged forests that will be negatively impacted by climatic change, opportunities will exist for the introduction of tree species and varieties not as susceptible to climatic change. This is one method of potentially ameliorating effects of climatic change and should be actively studied in terms of feasibility of screening species and varieties (families). In non-forest unmanaged ecosystems too, such as grasslands, the introduction of new species might be considered as a measure to ameliorate any negative effects of climatic change on native (or present) species. The costs of screening and species introductions needs study.

Plant species from both managed and unmanaged ecosystems must also continue to be screened for susceptibility to air pollution injury. 


\section{LAWRENCE LIVERMORE NATIONAL LABORATORY'S UNIQUE SCIENTIFIC CAPABILITIES FOR ADDRESSING RESEARCH NEEDS DESCRIBED IN "ITEM 1" ABOVE}

LLNL capabilities in support of the research strategies suggested above will be outlined in this section.

\section{A. LLNL Center for Accelerator Mass Spectrometry (CAMS)}

The LLNL Center for Accelerator Mass Spectrometry (LLNL-CAMS) includes an ultra-high sensitivity apparatus for the measurement of rare isotope abundances. A few million atoms of a rare isotope contained in a $100 \mu \mathrm{g}$ sample is sufficient for elemental abundance analysis. Ratios of isotopes down to a part per $10^{-15}$ can be measured in a few minutes per sample. Accelerator mass spectrometry therefore increases the sensitivity and accuracy of ${ }^{14} \mathrm{C}$ isotope measurements by several orders of magnitude, and also reduces sample size required and time of analysis by orders of magnitude, compared to ${ }^{14} \mathrm{C}$ decay counting methods. Importantly, the ${ }^{13} \mathrm{C}$ content of extremely small soil or plant tissues can also be accurately measured. This greatly reduces the need for large destructive sampling campaigns associated with other isotope measurement techniques. The small sample requirements of accelerator mass spectrometry mean that study sites can be sampled relatively frequently over long time periods without causing significant disturbance. LLNL-CAMS has an established analysis capability for quantifying isotopes of carbon (and many other elements), which is important to research outlined in 1.A, 1.B, and 1.E above.

LLNL-CAMS can make important contributions to determining soil carbon $\delta^{13}$ to assess recent shifts from $\mathrm{C}_{3}$-dominated to $\mathrm{C}_{4}$-dominated ecosystems or vice versa.

LLNL-CAMS can make significant contributions to quantification of $\Delta^{14} \mathrm{C}$ in present and archived soils in order to establish residence time of carbon in soils in various ecosystems. This measure is required to test model predictions of soil carbon turnover times and to directly estimate carbon residence time in soil at present and near-past environmental conditions. Pioneering work in this area has been conducted by LLNL scientists.

LLNL-CAMS can be used in conjunction with FACE experiments to estimate effects of elevated $\mathrm{CO}_{2}$ concentration on ecosystem carbon turnover times.

\section{B. Air Pollution and Climatic Change Exposure Facility}

A permanent air-pollution exposure facility that is well equipped to support controlled experiments designed to investigate the effects of altered atmospheric composition on plant growth and physiology has been established at LLNL. This can support research outlined in 1.I above. Greenhouse and nursery facilities are available for propagating needed stock material and maintaining our existing populations of pine varieties. Growth chambers are available for conducting controlled-environment experiments on plant growth and physiology. For large, whole-plant experimentation, open-top chambers are available for modifying the atmospheric composition of experimental plants. To 
investigate the effects of elevated $\mathrm{CO}_{2}$, we have a large, 14-ton $\mathrm{CO}_{2}$ receiver for largescale alteration of atmospheric $\mathrm{CO}_{2}$ concentration in open-top chambers and a smaller 2-ton $\mathrm{CO}_{2}$ receiver for alterations of atmospheric $\mathrm{CO}_{2}$ in our greenhouses. Presently, the site is set up to examine large ponderosa pine saplings growing in 120-liter containers, enabling examination of root systems more closely than is possible in the field.

LLNL has a long standing record of field and laboratory experience with regard to exposure of plants to air pollutants and elevated $\mathrm{CO}_{2}$. Furthermore, LLNL has directed and is capable of conducting long-term field exposure experiments, while providing facilities for laboratory conformation of field results. LLNL also has the equipment to develop extensive field exposure sites on plant species of small to medium stature using open-top chambers (we have 35 chambers). We have the ability and experience to establish these exposure sites at remote locations, and/or use the recently developed laboratory based site. We have also recently developed and built 100 state-of-the-science chambers for exposing branch tissue on mature plants of large stature, a capability which is only available at one other location in the US. These chambers are supported by numerous analyzers ( 11 ozone analyzers, eight $\mathrm{CO}_{2}$ analyzers, etc.), kilometers of tubing and power cables, and data acquisition systems. Finally, we have the research and development expertise to adapt facilities and exposure chambers to take into account differing temperature and precipitation regimes.

\section{Earth System Model (ESM) Framework}

The LLNL Earth System Model (LLNL-ESM) framework (and supercomputers, but the computers are available to anyone anywhere with a phone line) can be used to link LLNL and ORNL ecosystem models to climate models and geographic information systems (GIS's) to determine and advance the strengths of models at both laboratories. (Models from other laboratories, universities, and research institutions can also be assessed with the LLNL-ESM framework and incorporated into earth system models.) The LLNL modeling group is strong in the area of mechanistic biological models-including biological responses to elevated $\mathrm{CO}_{2}$ and climatic factors-and climate system models, whereas the ORNL group is focused on land-use change impacts on carbon cycling and aggregated ecosystem models. These approaches should be compared and coordinated. They might also be combined.

LLNL has a strong interest in a Global Vegetation Response Model and a Global Biosphere Productivity and Cycling Model (see 1.G above). We have an excellent capability in executing these programs due to our experience in developing a prototype ESM. The LLNL-ESM can serve all the modeling projects outlined above.

\section{Remote Detection of Effects of Global Change on Vegetation}

Because of the remote sensing capability developed by the Advanced Technology Program for the Strategic Defense Initiative, LLNL could make a unique contribution to remote detection of ecological effects of global environmental change (e.g., 1.A above). Likewise, because of our extensive collection of LLNL-developed and externally developed vegetation models, we are well positioned to support the analysis of the remotely sensed data (e.g., 1.E and 2.C above). 
Application of Advanced Technology Program's Remote Sensing Capability Developed for Defense Programs

The detector responsivity requirements for the visible wavelength portion of the HRSS spectral response can be adequately met using standard silicon CCD technology. A low mass $(0.35 \mathrm{~kg})$ space-qualified UV/Visible sensor has been developed that can meet the requirements of this sensor. For the near-infrared portion of the solar spectrum, an InSb IR focal plane array is ideal for this application. A low-mass $(1.7 \mathrm{~kg})$ space qualified sensor design, including optics, exists. This sensor uses a 12-bit A/D (large dynamic range) and incorporates a light-weight low power integral Stirling cryocooler. A version of this sensor coupled to a hyperspectral dispersion approach will meet the HRSS requirements (see 1.A above).

Several spectral discrimination schemes are available for the HRSS. One approach incorporates a linear wedge filter design. These filters enable high spectral resolution in a compact packaging form factor that allow integration of this element without significant perturbations to the existing sensor configuration. Another promising technology for hyperspectral discrimination uses a version of a Digital Array Scanned Interferometer (DASI). This represents a new type of imaging spectrometer that can provide hyperspectral discrimination using a compact birefringent interferometer design. This general class of Fourier transform spectrometers have a significant advantage over grating spectrometers in their greater throughput (or etendue). This greater throughput can be utilized and traded-off in the spectrometer design in several ways, but fundamentally this advantage results in very compact designs with typically 1-2 orders of magnitude more light gathering capability over conventional grating systems. The practicality of this spectrometer design has been demonstrated by several authors.

The sensor and spectral dispersion elements will be integrated into a common optical assembly and operated using a low mass high performance computing and data collection system that will process and telemeter in real-time the collected multi-spectral imagery. The entire HRSS will mass between $15-30 \mathrm{~kg}$, with a volume of less than $0.1 \mathrm{~m}^{3}$ and consume 100-200 W.

An experimental measurements program utilizing one of several possible candidate UAV platforms will be implemented. SERDP is currently sponsoring the Atmospheric Remote Sensing and Assessment Program for Global Climatic Change which is undertaking a series of atmospheric observations using the "Gnat 750" and the "PerseusB" UAV's. This program is fielding a series of compact radiometers and several passive and active instruments for atmospheric radiation balance measurements and satellite calibration experiments in cooperation/coordination with DOE's ARM program. Under SDIO/BMDO's Theater Missile Defense Program, LLNL is developing the "Raptor," a long endurance, high altitude UAV. Smaller mini-UAV's are also becoming available including the General Atomic "Prowler" and AAI Corporation's "Cyclone." As a result of the HRSS's low mass and small volume, even the smallest of the mini-UAV's can be considered as viable platforms for this instrument and opens the possibility of integrating the HRSS into either SERDP's atmospheric sensing program or other UAV measurement programs. 


\section{E. Modeling Community- to Landscape-Scale Response of Forests and Crops to Global Environmental Change}

A cutting edge, detailed, bottom-up (predictive) model of forest tree growth and ecosystem mass, energy, and momentum exchange is being developed at LLNL. A program of model testing using eddy correlation measurements at multiple field sites is underway (see also 1.D above). LLNL has also developed two state-of-the-science models of forest succession: SILVA, a gap model for mixed-conifer forests, and VISTA, a smallarea model of forest dynamics and spread. These models would allow us to move aggressively on the global change/forest modeling program outlined above. Also, the large elevated- $\mathrm{CO}_{2}$ experimental program using trees at LLNL can provide needed model parameters. Moreover, scientists at LLNL are developing and testing two of the most comprehensive models of crop ecosystem physiology and productivity.

\section{Models of Plant Physiology and Growth Available at LLNL}

LLNL has an extensive collection of models of plants, crops, and natural ecosystems that simulate the physiology and dynamics of plant growth throughout a growing season. These models include: BEETGROW, a simulator of sugar beet growth and development including the effects of elevated $\mathrm{CO}_{2}$ and $\mathrm{H}_{2} \mathrm{~S}$ on photosynthesis and growth; GROW1, parameterized for corn; SOYGRO, a soybean simulator, SYLAS, a soybean simulator that contains the effects of ozone on plant growth; TREE, a simulator of forest growth and development that combines FOREST-BGC and BACROS to assess effects of ozone and acid precipitation on forest growth; POTATO, simulates seasonal potato growth and development; and TERRA, a global model of productivity for 17 vegetation-types covering the globe. These models were either developed at LLNL or acquired from other institutions.

Of special interest is the model TERRA. TERRA is a model of ecosystem productivity and biogeochemical cycling covering the Earth's land surface with $1^{\circ} \times 1^{\circ}$ grid cells. The TERRA grid cell model consists of a set of ordinary, coupled nonlinear differential equations for water, carbon, and nitrogen dynamics. The grid cell models are calibrated to 17 field research sites. We developed the grid cell model as a local ecosystem productivity and biogeochemical cycling model. The local ecosystem model is a generic productivity-and-cycling model that calculates water fluxes of evaporation, transpiration, and runoff; carbon fluxes of gross primary productivity, litterfall, and respiration; and nitrogen fluxes of vegetation uptake, litterfall, mineralization, and system loss. The state variables are soil water content, carbon in live vegetation, carbon in soil, nitrogen in live vegetation, organic nitrogen in soil and litter, and available inorganic nitrogen aggregating nitrites, nitrates, and ammonia. The water balance model is based on DAYTRANS and the carbon and nitrogen cycling model is based on TEM. TERRA is an integral part of LLNL's Earth System Model (2.C).

\section{Forest Ecosystem Physiology Model}

A detailed mechanistic model of forest ecosystem physiology is under development. It is based on underlying biological and physical principles and simulates hourly 
photosynthesis, photorespiration, tree maintenance and growth respiration (leaves, boles, and roots separately), tree growth and development (leaves, boles, and roots separately), litterfall and root turnover (including biochemical composition of litter), forest floor and soil organic matter decomposition, soil water and heat transport, soil nitrogen transformations and transport, nitrogen uptake, solar mdintion absorption and ref ion, transpiration and latent heat exchange by trees and soli, sensible heat exchange rees and soil, longwave radiation balance of trees and soil, and ecosystem moment exchange. Because the photosynthesis submodel is based on the underlying chloroplast/cytosol/mitochondrion biochemistry, the model can be used to me predictions of forest response to elevated $\mathrm{CO}_{2}$ concentration (and temperatu-

The model is being independently tested with long-term whole-forest $\mathrm{e}$ jorrelation measurements at two forest sites. Future additional eddy correlation measurc...ent programs could also be used for model testing.

The canopy and soil physics and physiology portions of the model are generic and can be applied to other ecosystem types. Thus, the model would be a valuable tool in the interpretation of eddy correlation measurements of mass, energy, and momentum exchange made across a range of ecosystem types. The canopy and soil physics submodels could also be implemented in atmospheric circulation models to better characterize the influence of the terrestrial biosphere on global climate predictions.

\section{The LLNL Gap and Small-Area Models}

SILVA is based on JABOWA, the first individual-based model of tree communities simulating the dynamics on a forest stand dominated by a canopy tree, i.e., a gap model. SILVA has annual time-steps and simulates the establishment, growth, and death of individual trees over time scales of the order of a tree lifetime. Models built along these lines could be used to make long-term projections based on results from experiments conducted over at least one entire growing season, one time-step in the model. A gap model simulates the portion of a forest dominated by a dominant canopy tree. In a gap model, when a large, dominating tree dies, growth of the smaller trees is released. Many such models have been based on JABOWA. SILVA, includes detailed calculations of fire ecology.

The principal effect of fire in SILVA is tree death. SILVA calculates moisture content of fuels, dynamics of brush growth, dynamics of litterfall and decay, fire intensity, and probability of death due to fire. SILVA does not explicitly calculate nutrient cycling or the effects of nutrients on growth. Instead, these processes are implicitly imbedded in an expression for competition for edaphic factors.

Gap models have been used to investigate the community effects of elevated $\mathrm{CO}_{2}$ on

growth. Historically, these models have not included the other effects of elevated $\mathrm{CO}_{2}$ such as increased water-use efficiency or altered seed production.

The size of the tallest tree sets the scale for the stand area for the process of light competition. At the appropriate scale, the tallest tree dominates the stand. If the stand area is chosen too large, the tallest tree cannot dominate. If the r+nd is chosen too small, tall trees cannot be achieved because of crowding and root competition. The basic assumption of this type of model is that all the trees on the stand interact with each other and do not interact with any trees outside the stand. These results suggest that, at the appropriate 
scale, the error in making this assumption is negligible. Furthermore, the success of the many gap models at reproducing community structure suggests that the assumption of the non-interaction with trees outside the stand produces acceptable results for many forest systems.

We have constructed a model for small regions, VISTA, based on the idea that trees can be assumed not to interact strongly via shading and root crowding across stand boundaries. That is, many such stands adjacent to each other can be treated independently except for the weaker, long-distance interactions, such as seed dispersal. We divide a landscape into a grid of stands with each stand being a forest stand as used in the gap model SILVA; in each stand in the grid, we run an independent SILVA. Seed dispersal from each stand to surrounding stands depends on the strength of the seed production in the source stand. The density of dispersed seeds as a function of distance from the source is an empirical function. In addition to seed spread, we also allow the spread of fire over a region. Fire can spread from grid stand to grid stand in a stochastic fashion based on a probability of fire spreading to nearby stands from a stand which has a fire.

\section{Mechanistic ( $\mathrm{CO}_{2}$-responsive) Field Crop Models}

Two of the most comprehensive existing physiologically based models of crop physiology and productivity, one of wheat and the other of cotton, are being tested with data previously collected during several years of FACE experiments in Arizona (conducted by DOE/USDA). The models simulate most of the same processes listed for the forest physiology model above, with the addition of detailed grain and boll growth. Model testing will continue with future crop FACE experiments. As with the mechanistic forest physiology model, the photosynthesis and photorespiration routines are based on underlying biochemistry which make the model amenable to extrapolative predictions with respect to elevated atmospheric $\mathrm{CO}_{2}$ concentration.

\section{COLLECTIVE CAPABILITIES OF THE DOE NATIONAL LABORATORIES TO CONDUCT RESEARCH EMPLOYING NEW IDEAS AND METHODS OF STUDYING ECOLOGICAL EFFECTS OF GLOBAL ENVIRONMENTAL CHANGE}

Research required to address ecological responses to global environmental change should have the following characteristics.

(1) A multi-disciplinary approach. Scientists from many disciplines should collaborate and interact on the same set of experiments, observations, or models. For experiments, a mechanistic (multi-level) approach could then be used to search for integrated markers (biochemical, molecular, physiological, morphological, structural, or ecological) that could be used as indicators of success (or failure) in a future environment. A broader understanding of abiotic and biotic controls on ecosystem functions, using modern techniques such as remote sensing, and GIS's integrated with ground truthing and localized manipulative experiments and 
observations, is needed to integrate results of elevated- $\mathrm{CO}_{2}$ research on individual species into ecosystem models. Furthermore, climate-related experimental treatments should be developed in conjunction with climate and ecosystem modelers.

(2) Several research centers supported by multiple institutions. Research centers focusing on specific biomes (or processes), and that use similar (standard) techniques of measurement and observation, should be established. Research at multiple centers would serve as a method of cross-checking results and methodology. Different centers should study different systems or biomes, but each center should contribute to an inter-center program aimed at developing a mechanistic understanding of the effects of environmental change on terrestrial ecosystems at the global scale. Research centers should establish links to the larger network of scientific expertise, and move away from concentrating research programs at single institutions.

(3) Ecosystem studies of a long duration. Forest studies, for example, require a longterm commitment on a large scale. Moreover, ecosystem studies must provide numerous and realistic treatment combinations across life stages (seedlings and mature tissue), with ample replication.

The national laboratories, acting in concert, can provide the framework required for these traits. By proposing collaborative research among the laboratories, expertise and facilities exceeding that available at any one site could be utilized. The laboratories already have facilities and scientists that rival other sources such as universities and other governmental agencies, and a combined DOE laboratory effort could easily exceed capabilities available anywhere else. A combined laboratory effort could form the framework of a network of multi-disciplinary research centers.

\section{A. Biosphere Model Intercomparison Project (BMIP)}

Following the successful Atmospheric Model Intercomparison Project (AMIP), a Biosphere Model Intercomparison Project (BMIP) could be coordinated by DOE with participation from across the national laboratories (1.E above). The BMIP would include participation and support from outside DOE (e.g., universities, research institutions, and NSF), but DOE should support (and supervise) the core project and its infrastructure. The LLNL Program for Climate Model Diagnosis and Intercomparison (PCMDI) provides a good example of how such a project might be coordinated and run.

In a BMIP, biosphere models should be tested (and compared) by placing them through a series of defined simulations to examine their applicability to modeling ecological effects of global environmental change. LLNL LDRD is currently supporting the development of such tests using our prototype Earth System Model and framework (2.C). These tests require linking atmosphere, ocean, and terrestrial biosphere models. LLNL is unique among the laboratories in its ability to develop and execute such tests and is a natural location for the core project.

The need for a BMIP is clear, but the tasks will be many and difficult. The national laboratories have the potential to initiate and carry out this large and important multidisciplinary project. As a first step toward the creation of a BMIP, scientists from 
among the national laboratories should meet to outline the general goals of the project and the specific tasks to be conducted (but not worrying at this point too much about details such as the use of specific computer platforms or database managers). Such a meeting (or group of meetings) should take place in the near future and should be encouraged by DOE headquarters.

\section{B. Global Inventory and Models}

We believe that the global strategies outlined above (e.g., 1.G) are best performed at the national laboratories because of their scope and requirements of being executed with multidisciplinary teams. Little pieces of them could be subcontracted to universities but the overall management and most of the actual implementation would best be done at the national laboratories. This is because the laboratories can effectively organize the interdisciplinary teams required for global-scale models. Universities are not structured to field teams requiring central coordination and integration. The national laboratories have the core expertise to accomplish the mission outlined above.

\section{Regional Models of Ecological Effects of Global Environmental Change}

Regional modeling projects, e.g., 1.H above, can also best be implemented by the national laboratories. These projects could not be done by universities. Only the laboratories have the breadth of talent available to work on developing complete models of each of the regions (basins) of the US. Each basin should be assigned to a particular laboratory or laboratories with stringent requirements on products. A central modeling team should be set up to share models across the laboratories and to insure compatibility between model inputs and products and uniformity of model quality.

\section{Effects of Environmental Change on the Network of DOE Research Sites}

The DOE laboratories can make use of the extensive expertise scattered throughout the DOE network by advancing a program of DOE multi-site ecological research (e.g., 1.F above). Because of the special experience accumulated at the DOE research sites, this program could only be efficiently carried out by the DOE laboratories. Specific subprojects, however, could be turned over to university investigators. Because of the power of cooperating investigators in developing the site models, this project could become a model for the entire federal land ownership system and eventually be used to detect and project climatic change effects for the whole US.

Only DOE or NASA laboratories have the expertise in the required hardware to carry out these studies. Some submodels could be obtained from universities or modeling work subcontracted to universities for systems for which DOE laboratories did not have existing models. The DOE laboratory complex, however, has extensive modeling resources to draw upon for the successful completion of this project.

\section{E. Modeling Effects of Global Change on Forest Resources}

The collected capabilities of the DOE laboratory system would contribute significantly to 
a program of modeling effects of environmental change on forest resources because of the experience of the DOE investigators in different forest systems. For example, if three teams (or four or five) were chosen to work on such a program, each could develop a scaling progression of models unique to each area of the country for each team. From these resulting models, the three teams (or four or five) could extract the features of scaling that are in common across the forest systems from those features that are foresttype dependent. The more teams that work on this problem, the better would be the chances that commonality would emerge.

\section{NON-DOE ECOLOGICAL RESEARCHERS AND FACILITIES THAT COULD BE EFFECTIVELY UTILIZED BY THE DOE LABORATORIES}

The proposed program for a global biosphere inventory (1.G above) should be closely coordinated with existing national programs (e.g., EPA/EMAP and DOI/NBS), with international agencies (e.g., UNESCO), and the counterparts of the US program in other countries. In all other programs described above, non-DOE researchers could be used best in supporting the overall goals of each program by working on detailed subprojects that could be integrated into the overall program by the national Laboratories.

\section{A. University of California, and other California university, scientists}

LLNL could benefit greatly from collaborative research with ecologists and plant and soil scientists at each of the University of California (UC) campuses. There is considerable interest in ecological effects of global environmental change across the UC campuses. Links between UC faculty and LLNL are an obvious example of laboratory-university collaboration, in part because LLNL is managed by UC. Collaboration between university faculty and laboratory scientists has much to offer the universities because of the many large state-of-the-science experimental, measuring, and computer facilities at the laboratories that are not available directly to universities. The collaboration between universities and the laboratories should be viewed by funders (such as NSF) as particularly attractive because university faculty do not generally have access to the scale of facilities that can be used for ecological research available at the laboratories. In other fields, such as high energy physics and computing, collaboration between the laboratories and universities has been especially fruitful, and a case should be made for similar collaboration concerning ecological research. Funds available to individual university scientists could be pooled among many university personnel, and the laboratories, in order to support large-scale research that otherwise could not be conducted due to prohibitive costs and lack of interdisciplinary experience and skills at universities. In addition, interdisciplinary research has not historically been rewarded at universities whereas interdisciplinary research can more easily proceed at the national laboratories. The laboratories can play a central role in such collaborative efforts because the laboratories and the national environmental research parks can operate ecological research at the large scale required for much ecological research whereas universities are often more limited in terms of facilities due to their structure and objectives. Moreover, universities do not 
generally excel at interdisciplinary research, which is a particular strength of the national laboratories.

\section{B. University of California Natural Reserve System and Experimental Farm System}

The UC Natural Reserve System is a system of 30 relatively undisturbed samples of California's natural habitats and the facilities needed to support research. These reserves are available for research by national laboratory scientists. It is worth noting that California has more ecological diversity, agricultural productivity, and human habitants than any other state and many other countries, and that the UC reserve system offers research opportunities with many globally important biome types. Some of the reserves would be appropriate for new FACE experiments (1.B above). Moreover, California's agricultural research stations would be premier sites for studies of effects of environmental change on agriculture and other marketable goods provided by ecological systems. Many of the world's leading plant and ecosystem ecologists are on the faculties of the UC and other Califormia universities such as Stanford University and San Diego State University. Top-notch ecological research scientists at institutions such as the Carnegie Institution of Washington, Department of Plant Biology (Palo Alto, CA) are also easily accessible to LLNL.

\section{Chico, California Air Pollution and Environmental Change Exposure Facility}

The US Forest Service's Tree Improvement Center at Chico, California has over 2000 ponderosa pine trees representing clones (genetically identical trees) from over 200 families. These clones were obtained by grafting 70 -year-old tissue onto seedling rootstock. The result was trees that are physiological and morphologically mature, but substantially smaller in height. Ten years after the grafting, these trees are now 7-m tall and suitable for study of the effects of elevated $\mathrm{CO}_{2}$ or air pollution on genotype/environment interactions on mature tissue. Furthermore, because genetic and environmental differences between nearby seedlings and mature clones have been significantly reduced compared to a field setting, the effect of tree age on physiological and morphological responses to environment can more accurately be assessed. To date, we have installed 90 branch exposure chambers and 9 open-top chambers at the Chico facility.

\section{Blodgett Forest Research Station}

The University of California, Berkeley has an experimental forest in the Sierra Nevada that is ideal for studying elevated $\mathrm{CO}_{2}$ and air pollution effects on natural forest stands. This field site has both plantations and natural stands of six conifers, two hardwoods, and associated shrub vegetation. The newly developed LLNL branch exposure chambers can be used to conduct innovative experiments that link results from the Chico site to the responses of crown canopies for several species, and to study plant competition and density interactions. 


\section{ADVANTAGES AND DISADVANTAGES OF HAVING THE DOE LABORATORIES PARTICIPATE IN THE DEVELOPMENT OF COORDINATED MULTI-LABORATORY PROGRAMMATIC PROPOSALS, AS OPPOSED TO HAVING EACH LABORATORY SUBMIT INDEPENDENT PROPOSALS}

Arguments for cooperation among national laboratories are clear. By cooperating, DOE laboratories can combine strengths to produce excellence across a wider range of disciplines than can one laboratory alone. This could allow each laboratory to concentrate its personnel development into areas in which it desired to be particularly strong rather than to invest in breadth across all relevant disciplines. Thus, excellence in specific areas would be increased in importance and overlap among laboratories could be reduced.

Coordinated multi-laboratory efforts would provide the strongest possible proposals. For example, LLNL/ORNL collaborative modeling efforts cannot be matched at any university or research institution. The same is true for many aspects of experimental and observational programs related to ecological effects of global environmental change. The large number of ecologists at the national laboratories with expertise in global change issues could be unified into a team which would far surpass expertise available at any single university or research institution.

On the other hand, arguments against multi-laboratory proposals are also clear. Physical proximity-down the hall rather than across the country-is required for maximum productive scientific collaboration. Work occurring at one laboratory may in practice be independent from work at other laboratories. Multi-laboratory projects might really consist of only loosely coupled parts rather than truly integrated work.

Additionally, there is the problem of overcoming historic mistrust and competition among the national laboratories. The mistrust is built around the notion that cooperation today might enable your competitor, i.e., another national laboratory, to use that cooperation to her/his exclusive advantage later. One solution to this problem might be for DOE to become an honest broker among the laboratories. Perhaps a better way would be for DOE to encourage trial cooperative projects from the bottom up. The trial cooperative agreements could be among individuals at different national laboratories that already have personal relationships. In these cases, there might be existing trust around which to expand the development of larger scale collaboration.

Developing a multi-laboratory research program requires at least one leader with knowledge of all the national laboratories' capabilities and with a clear vision of what needs to be done to advance knowledge and solve problems. This leadership would ideally come from DOE headquarters. Otherwise, the laboratory with the lead scientist may become self-serving. DOE used a multi-laboratory approach in their recent ozone program. The approach was not successful, however, mainly because there was no strong leader who exercised self-criticism and evaluation of the structure of the collaborative effort in accordance with the goals of the program. 